\title{
The Implementation of Lifelong Learning in Family
}

\author{
Ihat Hatimah \\ Department of Non Formal Education, Universitas Pendidikan Indonesia \\ Bandung Indonesia \\ Ihat.hatimah@yahoo.co.id
}

\begin{abstract}
The initial idea of lifelong education stressed that individuals in the community can learn and should continue to learn on an ongoing basis. The presence of lifelong education is caused by the emergence of learning and educational needs that continue to grow and develop throughout the flow of human life. Lifelong education focused on the motivation of a person or group to gain learning experiences in a sustainable manner. The learning experience is taken consciously, programmatically, and systematically through the process of learning in order to achieve the learning objectives that have been determined. The function of lifelong education is as a force for motivating learners so that they can perform learning activities based on the encouragement and direction of itself in a way of thinking and doing in the world and life. The implementation of lifelong education in a family indicates that family education is one vehicle that can be taken by a person from the cradle to the end of life. Family is the first and major educational institution where a child receives the first education can shape the personality for times to come. Through the family, the parents and family members prepare everything needed by every family member of the family, which can be done through guidance, solicitation, modelling. The family has a crucial role to introduce customs, habits, rules, values or ways of life. Education in the family implies an effort to help children able to live as a human being who are able to develop themselves independently.
\end{abstract}

Keywords-Lifelong Education, Implementation of PSH in the Family

\section{INTRODUCTION}

A family is the smallest social organization but the most central place to educate its members. A family is where children are looked after, trained, protected and educated by their parents because these are the responsibilities of parents as the initial teachers of their kids. A family life is commonly the first life experience encountered by a child. In a family as well, a child experiences a lot of real life situations for his/her selfdiscovery and self-development. The situation of education in a family is an effort to create a more condusive family life which helps children attain the best learning experience for their selfdevelopment. This learning experience in further will help children absorb precious values that are beneficial to assist them facing the competitive future. Family education also supplied children with religious values, moral and social values as well as basic life skills. This notion is related to the Law of Republic of Indonesia No. 20/2003 on the National Education System which implicitely suggests that family education is a part of non-formal education which is held within families to teach their members about religion, cultural and moral values, and skills.

A family is essentially the central of education which aims to create wise and competent human beings, as well as faithful and devoted men to the God Almighty. Besides, the education is focused on the notion that people are individual, social and moral human beings. To grow these values in children's personality, the education in the families should be continuously conducted. As families play a central role in forming children's personality, family education should run as a lifelong process from birth until we die. Kids' noble characters can be possibly formed if their families function well as the first and central education for their children with the suitable parenting practices.

\section{DISCUSSION}

In one's life cycle, family is the first social institution which a child might be acquainted with. Children also start to know the world from their family.

Soelaeman argues that an education process occurs in a family as parents try to guide, drill, train and educate their children to be successful human beings who bring benefits to themselves, their families, their surroundings, and their countries. From pedagogical point of view, a family has the following characteristic: a family is a group of people where a couple of husband and wife share their affection under a legitimate marriage to be able to complement each other and enhance themselves. The process of enhancing themselves entails accomplishing their responsibility as parents to their children. [1]

Family education in a family unit is a process of introducing children to religion, cultural and moral values as well as basic life skills as the underpinning knowledge they should possess to interact with their surroundings. In terms of time and content of education, the role of parents in educating their children is boundless. The aim of family education is beyond the purpose of drilling children to talk, sing, or cook; it should supply relevant information and skills for their future needs. It is related to the needs of their future social life such as life etiquette, how to show care and affection to others, how to praise God, and the other norms related to the social life. The followings are the characteristics of family education: 1) the oldest educational institution, 2) an informal educational institution, 3) the first and the central educational institution, and 4) natural. 
Family is the oldest education place in the world. It is related to the existence of the first humans in the world, Adam and Eve, as the first family. Through a family, the process of inherintance of numerous values for the development of the children occurs. As an informal educational institution, family education is flexible in terms of its structure, learning materials, time, and teaching methodology. Family education is known as the first and the central educational institution for children because it is the first time they are introduced to values for the development of their personality. In other words, a family is the first institution which introduces cultural values, behaviours, norms and rules of life. Through a process of value internalization, children will know how to treat other people, how to respect others' right, and how to maintain social regulation. As family has a natural characteristic, the relation between parents and children should be based on natural affection. Imam Ghozali also highlights that a child is a mandate from God to parents, thus parents must educate their children as good as possible. The awareness of sincerety of parents in educating their children during the parenting process allows their children to grow better both physically and spiritually. The purpose of family education cannot be separated from four basic foundations as follows: 1) religion, 2) anthropology, 3) social and cultural values, and 4) psychology.

Religious values underlie the parents' actions towards their children that lead them to be religious as a guidance in their daily behavior. Anthropological values underlie human fairness in society, since family is the smallest unit in the society. Socio-cultural values underlie what should be done by parents to prepare their children so that they will be able to adapt and interact with the surroundings. It is based on the assumption that human beings are social beings who must be able to interact and adapt to the surroundings. Psychological values underlie the actions taken in an effort to provide guidance for children as an individual who has their own characteristics adjusted to the personal and development. Education in the family aims more towards the personal development of children, so that they have the ability to step onto the next stage and be a better individual in accordance with the norms.

As one of figures in Indonesian education, $\mathrm{Ki}$ HajarDewantoro states that: ".....family is a place that has better education in terms of quality and form compared to other education centers, to advance towards intelligence character education (individual character development) and to provide them with the ability to adapt for social life. .....parents in the family, with pure sanity, pure love, pure sincerity, as they deal with their children, it is clear that they cannot be compared with teachers, who are obliged to teach children because it is their duty to do so." The phrase has a very deep meaning, that family is the perfect institution to educate children, so parents must be able to carry out their duties. This is supported by the opinion of Jones and Wilkins that states: "the first social experience of children take place in the family, therefore parents, in particular, are the first and main social agents." [2]

Furthermore, Tylor explains that children are not an isolated individual, but rather a family member in which children education is totally different from children education in school. [3]

The education system in the family must be continuous through time, it is in accordance with Islam point of view, as the Prophet said that in educating children;

- Prenatal education

- Education during pregnancy

- Postpartum education

- Education in the early days of children's life

\section{- Lifetime education for children}

Based on those points, in the Islamic perspective, lifelong education means seeking knowledge and keeping learning from when one is born until he/she dies.

Lifelong education activities aim to develop human potential through supporting and continuous processes, which stimulate and empower individuals to obtain knowledge, values, skills, and understanding. All of them will be fully achieved in life and be applied confidently, creatively, and fun in a role, situation, and environment. [4]

Furthermore, Wang elaborates that the culture of lifelong learning is very flexible, creative, and responsive so that it is able to satisfy the needs of individual differences in a society[5]. Flexible means that a family should be able to implement various education strategies which suit their children, thus the messages of the education can be delivered effectively. The suitable strategies to be implemented are related to the parenting system of the parents. A democratic parenting for example can develop children self-confidence at best which further will help them grow their autonomy. On the other hand, an authoritarian parenting system will raise the level of dependency of children on their parents. Creative means that lifelong learning helps children to develop their creativity in various aspects of life in order to gain the best quality of life. Responsive is related to the ability of lifelong learning to help an individual to respond to every possible change in life.

The process of lifelong learning is the steps which someone, a group, or a society encounters in the process of searching, finding and developing knowledge, skills, attitudes, and appreciation and it occurs continuously throughout their lifetime to be able to adjust with the development of the era. The concept of lifelong learning also includes delivery methods, process, and techniques that should be used in to accomplish the learning process. Lifelong learning is formal, informal, and nonformal and should occur in a variety of settings [6]. The lifelong learning framework emphasizes that learning occurs during the entire course of an individuals' life. Formal education and training contribute to learning, as do non-formal and informal learning taking place in the home, the workplace, the community and society at large [7].

Lifelong learning is a sustainable process which entails interrelated elements of education based on individual's needs of lifelong education in his/her lifetime. Therefore, parents have to accomplish the following roles to be able to provide the best family education for their children: 
- The source and affection givers. Parents must give sincere love and affection to their kids to create such a democratic interaction within the family.

- Caretakers and protectors. Parents should be able to take care of their kids, as well as guide and educate them throughout their lifetime so that they grow as children who have noble characters and have positive life.

- The place to confide everything. Parents should be good listeners when their kids confide in them, so their kids will feel secure when telling everything to their parents particularly when they have some problems to solve.

- The manager of family life. Parents are required to have sufficient management skills to control their family so that the family members know their responsibilities.

- The supervisor. Parents are their children's supervisors who are responsible for guiding and directing their children to the right path of life. This way enables children to discover their true potential.

- The teachers of emotional quotions. Parents should teach their children how to develop their emotional quitions so they will grow as men who can control their feeling.

\section{CONCLUSION}

A family is the first and the central educational institution which a kid might encounter. Family education thus plays a significant role in children's development. A family has a role to take care of, to train, to protect, and to educate their children which should be accomplished by parents. The initial idea of lifelong learning arises due to the needs of education and learning of people throughout their lifetime. The implementation of lifelong learning in family shows that family is indeed the first educational institution which children commonly meet from birth until they die. A family is the first and the central educational institution where children firstly get the education to create their personality for their future life. Through a family life, parents and the other members of the family work hand in hand to prepare the future life of the members by giving proper education, guidance, assistance, motivation and good role model. A family also has the function to introduce children to the cultural values, habit and customs, norms and values which is done continuously. Overall, family education is essentially conducted to help children become better human beings who can develop themselves.

\section{REFERENCES}

[1] Ki Hajar Dewantara, (1977). Pendidikan (Bagian Pertama). Yogyakarta: Majelis Luhur Persatuan Taman Siswa.

[2] Scott-Jones, D. and Peebless-Wilkins, W. (1986). Sex Equity in Parenting and Parent Education, Theory into Practice, No. 4, Vol. XXV, Au-tumn.

[3] Denny Taylor. (1988). Ethnographic Educational Evaluation for children, families, and Schools, Theory into Practice, No 11, Vo. XXVII.

[4] European Commission. (2002). Directorate General for Education and Culture, European Report on Quality Indicators of Lifelong Learning. Brussel.

[5] Wang, C.Y. (2007). Advancing Lifelong Learning through Adult Education in Chinese Taipei.

[6] Christine, J. Cresson and Gary J. Dean. (2000). PAACE Journal of Lifelong Learning. Vol. 9

[7] Naierossadat Daneshvar Hosseini. (2006). Journal of College Teaching \& Learning. Vol. 3 Number 12 